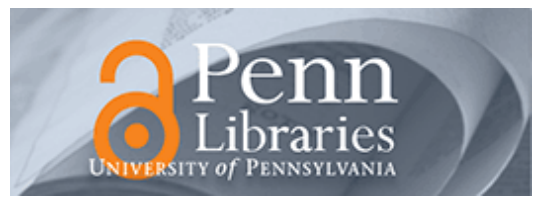

University of Pennsylvania

ScholarlyCommons

Marketing Papers

Wharton Faculty Research

June 1996

\title{
Publication of Research on Controversial Topics: The Early Acceptance Procedure
}

J. Scott Armstrong

University of Pennsylvania, armstrong@wharton.upenn.edu

Follow this and additional works at: https://repository.upenn.edu/marketing_papers

\section{Recommended Citation}

Armstrong, J. S. (1996). Publication of Research on Controversial Topics: The Early Acceptance

Procedure. Retrieved from https://repository.upenn.edu/marketing_papers/106

Postprint version. Published in International Journal of Forecasting, Volume 12, Issue 2, June 1996, pages $299-302$.

Publisher URL: http://dx.doi.org/10.1016/0169-2070(95)00626-5

This paper is posted at ScholarlyCommons. https://repository.upenn.edu/marketing_papers/106

For more information, please contact repository@pobox.upenn.edu. 


\title{
Publication of Research on Controversial Topics: The Early Acceptance Procedure
}

\begin{abstract}
Research with the potential to produce controversial findings is important to progress in the sciences. But scientific innovators often meet with resistance from the scientific community. Much anecdotal evidence has been provided about the reception accorded to researchers who have obtained controversial findings. While many of these cases occurred long ago (e.g., Copernicus and Galileo), the problem continues to the present. This problem has been addressed to some extent in that nearly all universities grant their faculty tenure to protect their right to publish their findings. Still, the right to publish one's findings does not remove the barriers to publication of controversial findings.

Perhaps the major barrier to publication is peer review. Peer review serves many useful functions such as correcting errors and providing a fair way to allocate journal space and research funds. But it also suppresses innovation. Below, I discuss how peer review affects the publication of controversial findings, discuss what is currently being done, and then recommend another solution to this problem.

\section{Comments}

Postprint version. Published in International Journal of Forecasting, Volume 12, Issue 2, June 1996, pages 299-302.

Publisher URL: http://dx.doi.org/10.1016/0169-2070(95)00626-5
\end{abstract}


Published in International Journal of Forecasting, 11, 1995, Notes: 1-4.

\title{
Publication of Research on Controversial Topics: The Early Acceptance Procedure
}

\author{
J. Scott Armstrong \\ The Wharton School, University of Pennsylvania
}

\begin{abstract}
Research with the potential to produce controversial findings is important to progress in the sciences. But scientific innovators often meet with resistance from the scientific community. Much anecdotal evidence has been provided about the reception accorded to researchers who have obtained controversial findings. While many of these cases occurred long ago (e.g., Copernicus and Galileo), the problem continues to the present. This problem has been addressed to some extent in that nearly all universities grant their faculty tenure to protect their right to publish their findings. Still, the right to publish one's findings does not remove the barriers to publication of controversial findings.
\end{abstract}

Perhaps the major barrier to publication is peer review. Peer review serves many useful functions s uch as correcting errors and providing a fair way to allocate journal space and research funds. But it also suppresses innovation. Below, I discuss how peer review affects the publication of controversial findings, discuss what is currently being done, and then recommend another solution to this problem.

\section{Effects of Peer Review on the Publication of Controversial Findings}

Papers with findings that challenge existing beliefs are often treated harshly by journal reviewers. For example, Gans and Shepherd (1994) examined the reception given, to new ideas in economics. In this paper, leading economists discuss their frustrations because their best work has often received unfavorable reviews.

This perception of a bias against innovative findings was found in a systematic survey of applications for National Cancer Institute funding in 1980. Respondents were asked about their attitudes toward reviewers. For example, in response to the question whether reviewers were "biased against women and/or minorities," only $4.9 \%$ of the 336 respondents agreed. When asked whether reviewers were "reluctant to support unorthodox or high-risk research," 60.8\% agreed (Chubin and Hackett, 1990, p. 66).

In a survey of the editors of 16 leading American Psychological Association journals, Armstrong and Hubbard (1991) found that the editors were discouraged because few papers with controversial findings were submitted. Furthermore, of those submitted, few were favorably reviewed by the referees. For the two year period covered by the survey, only one paper with controversial findings had received all favorable reviews. (In this case the editor told us that he was determined to publish the paper so he sought out referees who would provide favorable reviews.) This represents one favorably reviewed paper for 32 "journal years."

Reviewers arc unlikely to say they reject a paper because they disagree with the findings. They are probably not even aware of such a prejudice. However, experimental studies (Goodstein and Brazis, 1970; Abramovitz et al., 1975; Mahoney, 1977) show that such a bias does exist.

This prejudice poses a risk for those who would study controversial topics. For example, the findings about the poor predictive performance of Box-Jenkins procedures were greeted with a negative response (e.g., see the commentary on Makridakis and Hibon, 1979). Some researchers even thought that these findings should not have been published. 


\section{Current Procedures for Dealing with Controversial Findings}

The International Journal of Forecasting (IJF) has taken steps to encourage the publication of papers with controversial findings. These procedures are provided on the inside front and back covers of every issue. One procedure is unusual among scientific journals is "results-blind reviewing." At the author's discretion, a paper can be submitted for review with the results withheld from the referees. Unfortunately, few authors have used it. This is partly because few papers with controversial findings are submitted for review. When results-blind reviewing has been employed, it has been at the urging of an editor.

The $I J F$ also encourages authors of papers to submit a list of possible reviewers with the promise that at least one will be asked. On occasion, the $I J F$ has also published the reviewers' comments along with a controversial paper. This allows for a debate on the controversial nature of the findings. For example, the finding that the MSE should not be used for comparing the forecast accuracy of different forecasting methods was controvers ial, and two papers that reached this conclusion were published along with commentary (Armstrong and Collopy, 1992; Fildes, 1992).

\section{Early Acceptance Procedure}

Work on important topics poses some risk to researchers. The referee's evaluation of a study often depends on whether it agrees with prior findings. One way to reduce the risk to the researcher is to review a paper for publication based on the design of the study. Thus, the review can be done before the study is conducted. This idea has been around for some time (e.g., Rosenthal (1966) raised it as a possibility for reviews in psychology, and Walster and Cleary (1970) expanded on it), but, to my knowledge, it has not been used by journals in the social sciences.

The Early Acceptance Procedure means that the paper will be published if the design procedures are implemented. This decision would be made irrespective of the results. Of course, if the design changes during the course of the study, it may be necessary to re-review the design.

There are some advantages to early acceptance as far as the reviewing process is concerned. First, it avoids the bias that occurs when the results conflict with the reviewer's expectation. Second, it is expected to focus attention on the substantive importance of the problem that is being investigated. And third, it helps to avoid the bias against studies that do not achieve statistically significant results (e.g., see Hubbard and Armstrong, 1992).

The Early Acceptance Procedure should also be beneficial to the researcher. The reviews may lead to suggestions that improve the design of the study, and these can be implemented before conducting the study. Secondly, the researcher does not have to invest nearly as much time and effort to find out whether the paper will be published. These advantages can reduce the risk to a researcher who is trying to decide whether to undertake the study of an important topic.

There are also advantages to the field. It is widely believed, for example, that researchers sometimes revise their theory after analyzing the data, and that they do not inform the reader that the theory is ex post. In fact, I have had journal reviewers suggest that I should revise the theory to provide a better explanation of the results of one of my studies. By presenting the design for review, the prior theory is clearly recorded.

In view of the potential for publishing even a small number of papers with controversial findings, the editors of $I J F$ have authorized me to conduct a trial with an Early Acceptance Procedure. I can accept up to three papers during this trial. Here are some ideas about what papers would be of interest:

1. The designer should make a case that the problem is important to either practitioners or researchers.

2. The paper should be useful no matter what the outcome. That is, it should also be of some importance if it supports current beliefs.

3. The design should examine competing hypotheses, and, in doing so should be powerful enough to distinguish among them. A power analysis may be helpful here, and multi-study design are useful. 
4. The details of the design should be made operational so that when the study is completed, one can look back to ensure that the proper steps were followed.

The reviews under the Early Acceptance Procedure will use the standard referee's rating form (omitting, of course, the question about how surprising the results are). In addition, the re viewers will be asked to rate the importance of the topic to practitioners and to researchers. And whether the direction of the outcome would influence their opinions about importance. Finally, reviewers will try to predict the outcome of the study. In effect, we will use the same procedure as currently employed for results-blind reviewing of papers where the study has been completed.

This review will not be blind with respect to the author's name for two reasons. One of the best predictors of whether a person can successfully conduct research is that person's prior success as a researcher. Abrams (1991) noted that the correlation between prior citations for an author and later citations for that author is high. This suggests that a researcher's prior record should be a good predictor of success on a new project. (Interestingly, in these National Science Foundation proposals, the prior records of the researchers were provided, but they received too little weight.) The second reason for including the author's name is that it may be helpful for the reviewer to contact the author about design questions.

My hope is that this Early Acceptance Procedure will encourage controversial topics. To my knowledge, no journal has used such a procedure. I anticipate that the scientific benefits of publishing a paper with controversial findings will outweigh the risks of publishing a paper with erroneous findings.

\section{References}

Abramovitz, S. I., Gomes, B. and Abramovitz, C. V. (1975), "Publish or politic: Referee bias in manuscript review," Journal of Applied Social Psychology, 5, 187-200.

Abrams, P. A. (1991), "The predictive ability of peer review of grant proposals: The case of ecology and the US National Science Foundation,” Social Studies of Science, 21, 111-132.

Armstrong, J. S. and Collopy, F. (1992), "Error measures for generalizing about forecasting methods: Empirical comparisons," International Journal of Forecasting, 8, 69-80 (commentary follows to p. 109).

Armstrong, J. S. and Hubbard, R. (1991), "Does the need for agreement among reviewers inhibit the publication of controversial findings?," Behavioral and Brain Sciences, 14, 136-137.

Chubin, D. E. and Hackett, E. J. (1990), Peerless Science: Peer Review and US Science Policy. State University of New York Press, Albany.

Fildes, R. (1992), “The evaluation of extrapolative forecasting methods,” International Journal of Forecasting, 8 , $81-98$.

Gans, J. and Shepherd, G. B. (1994), "How are the mighty fallen: Rejected classic articles by leading economists," Journal of Economic Perspectives, 8, 165-179.

Goodstein, L. D. and Brazis, K. L. (1970), “Credibility of psychologists: An empirical study,” Psychological Reports, 27, 835-838.

Hubbard, R. and Armstrong J. S. (1992), “Are null results becoming an endangered species in marketing?" Marketing Letters, 3, 127-136.

Mahoney, M. (1977), "Publication prejudices: An experimental study of confirmatory bias in the peer review system," Cognitive Therapy and Research, 1, 161-175. 
Makridakis, S. and Hibon, M. (1979), “Accuracy of forecasting: An empirical investigation” (with commentary), Joumal of the Royal Statistical Society: Series A, 142, 97-145.

Rosenthal, R. (1966). Experimenter Effects in Behavioral Research. Appleton-Century-Croft, NY.

Walster, G. W. and Cleary, T. A. (1970), “A proposal for a new editorial policy in the social sciences,” American Statistician, 24, 5-10. 